\title{
The Challenging Experiences of International Students in South Korea: The Neo-Racism Perspective
}

\author{
Luis M. Dos Santos
}

Woosong Language Institute, Woosong University, South Korea

Received October 7, 2020; Revised November 10, 2020; Accepted December 6, 2020

\section{Cite This Paper in the following Citation Styles}

(a): [1] Luis M. Dos Santos, "The Challenging Experiences of International Students in South Korea: The Neo-Racism Perspective," Universal Journal of Educational Research, Vol. 8, No. 12B, pp. 8102-8109, 2020. DOI: 10.13189/ujer.2020.082612.

(b): Luis M. Dos Santos (2020). The Challenging Experiences of International Students in South Korea: The Neo-Racism Perspective. Universal Journal of Educational Research, 8(12B), 8102-8109. DOI: 10.13189/ujer.2020.082612.

Copyright $\mathrm{O} 2020$ by authors, all rights reserved. Authors agree that this article remains permanently open access under the terms of the Creative Commons Attribution License 4.0 International License

\begin{abstract}
Studying abroad is one of the significant life-changing decisions of many traditional-age students. Due to the ideas of globalisation and pop-culture development, South Korea becomes one of the popular destinations for tertiary education. Based on the conception of neo-racism, many international students may face discrimination due to their nationalities, religious practices, spoken languages, place of origin, gender, and personal characteristics. The purpose of this study is to investigate and understand the challenges and difficulties of international students in South Korea. The study was guided by one research question, which was, based on the perspective of neo-racism theory. How would international students who are currently enrolled at one of the South Korean universities and graduate schools describe their challenges and difficulties as foreigners? Based on the phenomenological approach, 100 participants who are currently enrolled at one of the South Korean universities and graduate schools were invited to share their life stories through individual interview, item sharing, and focus group activities. The results indicated that nationalities, place of origin, religious practice, personal characteristics, and sexism are some of the significant elements and challenges as foreigners and international students in South Korea. The outcomes of this study suggested that the government agencies should coordinate with the school leaders, local community offices, NGOs, and researchers to reform and polish their current policies and regulations for international students and professionals to overcome the challenges. More importantly, the Ministry of Education and school leaders should promote appropriate education schemes and programmes for intercultural
\end{abstract}

understanding and education.

Keywords Discrimination, International student, Neo-Racism, Sexism, South Korea, Stigma

\section{Introduction}

South Korea is one of the popular destinations for international students to pursue their education in the East Asian region. A report indicated that 160,165 international students were registered at one of the 430 South Korean universities and graduate schools during the 2018/2019 academic year. The current number is the highest since the late 1990s when the information has been established by the National Institute for International Education sponsored by the Education Ministry in South Korea [1]. The number of international students in South Korea is not surprised by the public members as the South Korea government offers a large number of scholarships and grants to students from different parts of the world. According to the government report, the South Korean government offers various types of scholarships to more than 6,000 international students from nearly 150 nations since the late 1960 s with about 2,000 scholarships per year [2].

During the last decade, the development of popular culture, the growth of the economy, and the promotion of medical tourism allowed the international communities knowing the existence of South Korea besides China and Japan in the East Asian region. These changes have 
established the international students and foreign professionals' awareness along with new workforce and students to the South Korean region.

The ideas and developments of globalisation allowed international students and foreign professionals to work and study in a foreign country and region. South Korea has taken advantage of the enrolment management of international students and professionals [3]. Besides the traditional apprenticeship and vocational-based training, universities and graduate schools take the important position to provide liberal arts education, tertiary-level training, and postgraduate-level education for the present and potential human resources and manpower for the domestic and international communities, society, government(s), and organisations. Previous studies [4] indicated that universities and graduate schools provide an effective way and direction for the development of the counties and regions. As a result, the South Korea government always establishes ways and plans to attract potential workforce and human resources to their region.

One of the attractive points for South Korean universities and graduate schools would be the development of information technology due to the recent growth of the home equipment and cell phone technology [5]. Young people and scientists want to study abroad in order to gain global understanding and intercultural skills for personal enhancement.

Another attractive point for South Korean universities and graduate schools would be the development of pop cultures in the entertainment industry [6]. It is not uncommon for many young people to watch Korean drama and TV shows, and listen to Korean music (i.e. known as K-Pop) due to the recent development of social media applications. Many young people would like to live in South Korea due to Korean pop stars and music.

Also, a large number of Korean junior colleges and universities established different types of exchange programmes and study plans for international students to experience and complete several semesters in South Korea. For example, according to a recent report from the National Institute for International Education [7], the South Korean government always establishes scholarships and even living stipends (i.e. living expenses, settlement allowance, round-trip airfare, and medical insurance) to international students, particularly the exchange students. Besides the government funding, a large number of junior colleges, universities, and graduate schools provide scholarship and funding to exchange students who study their programmes with at least one semester. Therefore, due to the financial supports, many students would like to come to South Korea for affordable education [8].

Not until the recent decade, South Korea becomes one of the popular regions due to the entertainment industry, such as Korean drama and Korean music [6]. In other words, the South Korean community has been homogeneous (i.e. single cultural community) throughout the regional development. In additional report [3] indicated that due to the geographic isolation and political powers between China and Japan, the Korean culture was isolated and developed inside of the Korean peninsula. Although both Chinese and Japanese cultures had influenced the Korean behaviours and developments, Korean people tend to advocate their own isolated culture. Therefore, many South Korean people are not prepared for foreigners and international cultural exchanging [3]. As a result, many international students and foreign professionals reported discrimination, stigma, sexism, and racism from the South Korean residents [9]. A previous study [9] investigated 118 Asian international college students in South Korea about their stories of discrimination, ethical problem, and mental distress. Although Asian students may have a similar social-cultural background with the South Korean residents, many had found that the South Korean residents disliked and discriminated their nationalities and personal characteristics due to their foreign identity. More importantly, many indicated that their experiences in South Korea were unfair, depressed, confused, and negative.

Another previous study [10] also found that two kinds of discrimination and stigma were given to foreigners in South Korea (i.e. personal rejection and unfairness). For example, many South Korean residents disliked and judged the foreign cultures from international students as their cultural practices are not the same as the South Korean culture. Although the judgement (i.e. from the South Korean residents) might not be ethical and reasonable, many foreigners felt negative as their personal characteristics were attacked. On the other hand, due to the nationalities and place of origin, Asian international students experienced unfairness and judgement as South Korean residents do not believe they should be respected [11].

Not only international students in South Korea, foreigners in the education profession also face discrimination and stigma due to their foreigners' identity. A previous study [11] investigated Black education professionals in South Korea. The results found that Black educators experienced unfairness due to their skin colour and nationalities. Many South Korean residents challenged the relationship between their skin colour and nationalities. For example, South Korean residents believed Black people should only belong to African countries.

Another previous study [12] also investigated the discrimination problems among the foreign language teachers in South Korea. The participants reported that skin colour and nationality ranked as the top difficulties for their living experiences in South Korea. Although many indicated that the educational institutions in South Korea offered them career developments and opportunities, many would leave the region after their 
contract due to the negative experiences.

\subsection{The Purpose of the Study}

There are many studies and projects about the programme evaluation, enrolment management, financial management for the university departments, and international students' statistics [9], [13]. However, many of these programmes do not investigate the challenges and difficulties when international students live and study in South Korea. Although the number(s) of international students at one of the South Korean universities and graduate schools is(are) not significantly high based on the statistics from the government agency [8], it is important to understand how the experiences, expectations, and living standards of these groups of people with the different social-cultural background and spoken languages [1].

According to result reports [2], [7], [8], Chinese student population remains the highest international students' population in South Korea. The Chinese student population accounts nearly $45 \%$ of the total population (i.e. 71,064 or $44 \%$ ), followed by Vietnamese students (i.e. 37,425 or $23.4 \%$ ), Mongolian students (i.e. 7,381 or $4.6 \%$ ), Japanese students (i.e. 4,392 or 2.7\%), and American students (i.e. 2,915 or $1.8 \%$ ). As a result, it is important to understand the experiences and sharing of these groups of international students in South Korea.

\subsection{Research Question}

In order to investigate and understand the challenges and difficulties of international students in South Korea, the study was guided by one research question, which was,

(1) Based on the perspective of Neo-Racism, how would international students who are currently enrolled at one of the South Korean universities and graduate schools describe their challenges and difficulties as foreigners?

\subsection{Theoretical Framework: Neo-Racism Theory}

The neo-racism theory [14] (i.e. cultural racism) refers to a non-traditional way of discrimination based on people's nationality, birthplace, place of origin, and religious practices etc. (i.e. beyond skin colour). The ideas and directions of neo-racism were created during the 1980s from different sociologists and philosophers in the western communities. This theory was employed in many studies with the focuses on minorities, foreigners, rural residents, gender issues, diaspora, social status, and stigma in our communities. Unlike the traditional idea about racism (i.e. mostly about skin colour and race), social level, social status, and the social caste system become some of the significant elements for discrimination due to the globalisation and international movements of both domestic and international residents [15].

During the past centuries, residents tended to stay in their local region due to the limitation of transportations and opportunities. However, as many individuals may need to work and study in different locations (i.e. other than their local regions and home country), the discrimination based on people's nationality, birthplace, place of origin, and skin colour became significant nowadays [15]. Some scholars and schools argued that the majorities believe their cultural behaviours and backgrounds are better than the minorities. In the society with the problems of skin colour and racism discrimination, the majorities may believe their cultures and backgrounds are better than others (i.e. in the United States, White people may think their cultural behaviours and backgrounds are better than the minorities) [16]. On the other hand, beyond the problems of skin colours, individuals with the same skin colour and racial background may experience discrimination and stigma due to their cultures. This discrimination, therefore, was defined as neo-racism. For example, both Chinese and Korean students have the same skin colour due to geographic development. However, the cultural, language and behaviours can be the keys for discrimination. In this case, the ideas and notions of neo-racism are established [14-16].

In this study, the applications of neo-racism allow researchers, policymakers, government officials, NGOs leaders, and even education staff to understand the challenges and difficulties of international students in one of the South Korean universities and graduate schools from the perspective of neo-racism [16]. Although the South Korean government always promotes the region as one of the open-minded communities for international students and foreign professionals for career development and promotion, it is not uncommon that some challenges and issues would happen due to the social and cultural differences. Therefore, the application of this neo-racism theory would be appropriate to seek the problems and issues in this area [15].

\section{Materials and Methods}

The qualitative research method has been employed for this study. Qualitative research studies [17] mainly focused on the sharing, life stories, personal understanding, in-depth conversation, and experiences of the participants. As this study sought to understand the living experiences of international students in South Korea, the qualitative research method would be appropriate for data collection and analysis.

The phenomenological approach [18] was chosen because the style focused on the individuals' understanding of their social world and how their experiences describe their experiences. Also, the study 
invited participants all over South Korea (i.e. but not a single or several universities and graduate schools). Therefore, the wider application of the phenomenological approach matched the recruitment nature of this study.

\subsection{Participants}

100 participants were invited to this study. The snowball sampling strategy was employed in order to recruit students from different regions and locations in South Korea. First, based on the network of the researcher, the researcher invited 20 international students (i.e. non-South Korean citizens) for the first-round recruitment. Each participant was asked to refer at least one participant for this study (i.e. international student). After several rounds of recruitment, a total of 100 participants were recruited for this study.

The participants should meet the following criteria.

(1) International students who are currently enrolled at one of the South Korean universities and graduate schools;

(2) Non-South Korean citizen;

(3) Have lived and studied in South Korea for at least one academic year.

\subsection{Data Collection}

Two separated interview sessions, participants' personal item sharing, and focus group activities were engaged for the data collection procedure. Based on the application of the neo-racism theory [14], the in-depth interview session(s) had been used for the data collection.

First, for the interview sessions, in fact, due to the recommendation of the social distancing, the South Korean government encouraged most types of face-to-face meeting for the purpose of illness. Therefore, the distance-based interview sessions were used (i.e. Zoom-based interview sessions). During the Zoom-based interview sessions, based on the neo-racism theory [14], each participant was asked about his/her reasons, motivations, understanding, experiences, sharing, personal stories, and conceptions about his/her academic and living experiences in South Korea. The open-minded and semi-structured interview questions were asked. It is important noting that the interview questions were developed based on the neo-racism theory. Therefore, the interview questions mostly focused on the challenges and difficulties as foreigners and international students in South Korea.

Second, during the interview sessions, participants were encouraged to share their personal items and remarkable things for support.

Third, after the participants completed two sessions of the interview sessions, they were asked to join a distance-based focus group activity for group discussion. Ten focus group activities were formed (i.e. ten participants per group). During the focus group activities, all were invited to share their ideas and experiences as foreigners and international students in South Korea. As many of the participants do not know each other, they could share their real information and conceptions as much as possible without any limitations.

\subsection{Data Analysis}

The general inductive approach [19] was employed for this study. The general inductive approach allowed the researchers to gather the large-size data into meaningful themes and subthemes.

First, after several rounds of data collection procedures, the researcher gathered more than 600 pages of written transcripts. Therefore, it is important to reduce the information to themes and subthemes. The researcher employed the open-coding strategy for first-level themes and subthemes.

Second, the researcher further employed the axial-coding strategy to reduce the themes and subthemes. As a result, two themes and three subthemes were merged for this study.

\subsection{Triangulation}

Some researcher may argue the validity of qualitative research data [17]. Therefore, the researcher employed multiple tools for data collection, including two separated interview sessions, personal item sharing, and focus group activities in order to reduce the concern.

\section{Results and Discussions}

Based on the lens of the neo-racism theory [14], this study followed the direction of the phenomenological approach to investigate the academic and living experiences of international students in South Korea. Through this qualitative inquiry, the researcher was able to merge the data to different themes and subthemes for the understanding of the social issues and problems, in this study, the international students' challenges and difficulties are from the perspective of neo-racism theory. The analysis of the interview sessions, personal item sharing, and focus group activities, the researcher yielded two themes and three subthemes under the perspective of neo-racism theory. Please refer to Table 1.

Table 1. Themes and Subthemes

\begin{tabular}{|c|c|c|}
\hline \multicolumn{2}{|c|}{ Themes and Subthemes } \\
\hline 3.1. & & The Sins of my Nationality \\
\hline & 3.1 .1$. & Discrimination due to the Place of Origin \\
\hline & 3.1 .2$. & Discrimination of my Religious Practices \\
\hline 3.2. & & The Sins of my Personal Characteristics \\
\hline & 3.2 .1$. & Sexism \\
\hline
\end{tabular}




\subsection{The Sins of My Nationality}

Based on the data from different channels and tools, all 100 participants experienced discriminations based on their nationalities. In fact, based on the South Korean government policies, students from different parts of the global communities are allowed to come to study in one of the South Korean universities and graduate schools. Therefore, many international students with different nationalities, social-cultural background, religious practice, and living styles come to South Korean annually for academic purposes. Although the government established policies for academic development [12], many local residents, local offices, school departments, and NGOs are not prepared for people with different backgrounds. For example, based on the lens of neo-racism theory [14], a large group of East Asian participants expressed their challenges and difficulties due to their nationalities. First, all Chinese participants said that South Korean people dislike Chinese people due to the recent COVID-19 pandemic, several sharing was captured,

I was called the virus woman on the street by many Korean residents...this is not a single case, I was called a virus woman every day in Seoul...I called the Seoul Metropolitan Government hotline for this issue...but they don't care my request and asked me to shut up...(Participant \#3, Chinese, Focus Group Activities)

\subsubsection{Discrimination due to the place of origin}

According to a previous study [20], racism and discrimination are not uncommon in the higher education environment [9], particularly elements from the neo-racism perspective, such as place of origin. Due to the requirement of their academic programme, many students need to complete an internship and/or placement for graduation. However, site supervisors consistently ignore the questions and needs of non-Korean students due to their foreign status. For example, some interned sites may have foreign language clinics and workplaces due to the nature of the multilingual services that they provide. However, site supervisors purposely never assign the right language speakers to the appropriate sites [21]-[25].

I can speak Chinese and I told this to the site supervisors for the Chinese interned rooms and sites...but the supervisor did not listen and pretended that...she cannot understand my broken Korean and English...instead, the supervisors assigned Korean students who cannot speak Chinese to the Chinese interned sites...

With the reflection of a previous study [3], Chinese students and individuals experienced discrimination, stigma, and bias due to their Chinese nationality. In fact, due to the historical and political issues, South Korean residents usually do not have positive feeling and attitudes toward the Chinese government and people. In this case, the Chinese participants experienced discrimination based on their nationality and place of origin. The discrimination and stigma, therefore, reflected the ideas of neo-racism [14] in particularly.

Besides Chinese participants, some participants from the central Asian regions and countries also expressed some similar discriminations, stigma, and bias due to their nationality said,

I expected to work in the Russian site as my second language is Russian...but the teachers ignored my requests and told me that I have to listen to the arrangement... as I am a foreigner, I have to listen to the arrangement of the Korean management....I have no rights...

With the reflection of a previous study [26], Korean instructors in the higher education sectors have the intention to categorise and compare students based on their language, religious practices, nationalities, and place of origin. The experiences from the participants, therefore, matched and confirmed with the previous literature.

\subsubsection{Discrimination of my religious practices}

Religious discrimination [21]-[25] toward both local Korean residents and foreigners is not uncommon in South Korea based on the previous study [27]. With the reflection of two previous studies [27], [28], religious practices are another significant basis of discrimination, bias, and stigma based on the lens of neo-racism theory. Many Muslim participants claimed that Korean people like to make fun of their religion and their forms of worship, such as the Salah (i.e. the formal, obligatory prayers of Islam). One said,

The Five Pillars are the most important practices of my religion (i.e., Islam). But some Korean people called the Mosque the Onion Head Church or the place of terrorists ...they brand all Muslim men, as well as women who wear the hijab, as extreme terrorists who will be harmful to their city...

More importantly, many indicated that some Korean people served pork dishes to Muslim people deliberately. One said,

I told the restaurant servants I cannot eat pork because of my religious practices...but many chefs served minced beef with pork or vegan dishes with pork oil on purpose...I have to say on purpose because this happened three times...that is not an accident...

According to a previous study [29], in 2006, the Korean government set out its plans to establish the intercultural and multicultural communities for international students, professionals, and workers to the region in order to satisfy the needs of human resources and manpower problems. However, both governmental plans and community-based schemes were not appropriately exercised due to the closed-mind of the local residents [30]. Based on the 
findings of the study and the sharing from the participants, the hate speech and the ideas of racism and neo-racism [21]-[25] highly limited their academic and living experiences in the Korean community.

\subsection{The Sins of my Personal Characteristics}

Besides nationalities, place of original, religious practices, and spoken languages, participants experienced sexism and ageism from their South Korean academic and living experiences. With the reflection of a previous study [31], the research indicated that female's rights are not significantly considered in South Korea due to the traditional conceptions of East Asian practice. Although cultural norms and practices should be respected, many participants expressed negative sharing from their academic and living experiences.

\subsubsection{Sexism}

More than half of participants (i.e. both male and female individuals) reported the unfairness and the lack of support from university services to school leaders. Although a previous study [10] indicated that the higher education institutions in South Korea always encouraged international students and non-Korean speakers for education and development, many of the university departments and services are not ready for non-Korean speakers based on the results of this study. The results of the investigations indicated the university services were always pro-Korean. Several were asked to drop out of their courses or leave the university if they do not want to give up some of their rights to Korean students,

Sometimes, I think my supervisor wants to control my life...I am an adult and I should have my own decision and thinking...But I have experienced some negative things...my supervisor asked me to leave the school if I didn't want to accept Korean gender norms ...he told me that females must give up their rights to males because we are females...

Besides, several participants reported the discrimination and unfairness to the school counsellors for further management and arrangement [32]. However, all these participants did not receive any positive results and arrangement due to their gender and nationality, said,

Even though I was being bullied and orally harassed by several Korean classmates because of my gender [i.e. female] and nationality...the Korean counsellor told me that I had to accept this because I am not Korean ... and because foreigners do not understand Korean culture or gender practices...

In conclusion, based on the lens of neo-racism theory [14], many participants experienced different levels and types of discrimination and stigma based on their nationalities, religious practices, spoken languages, place of origin, and gender. Although many sought help and feedback from many channels, the results were not effective due to the social-cultural misunderstanding between different parties in South Korea. With the reflections of previous literature, international students in South Korea usually faced different challenges, particularly from academic and language challenges. This study indicated that the elements from neo-racism theory, such as nationalities, languages, religious practices, gender, and place of origin might become one of the challenges for international students and professionals.

\section{Limitations, Future Research Directions, and Conclusions}

\subsection{Limitations and Future Research Directions}

The researcher concluded five limitations of this study. The current study focused on international students' academic and living experiences in South Korea. However, as students from different regions, religious practices, and language backgrounds may have different feedback and expectations. Future research projects may focus on one particular group of individuals, such as Muslim students in South Korea, in order to increase the concentration and focus.

Second, the current study only focused on the academic and learning experiences for international students in South Korea. Unlike other large-size countries and regions with high-percentage of the international population within their higher education system, the international backgrounds (i.e. nationalities, religious practices, and language backgrounds) may not be able to cover most of the international students. Therefore, future research studies may focus on the statistics and students' population in the East Asian region in order to cover a larger population of international students.

Third, some scholars may argue that the current technology and social media application can influence the experiences of international students. However, as this study mainly focused on the issue about the neo-racism and cultural related issue, the focuses about technology and social media application have been neglected. Therefore, future research studies may investigate how social media may influence the experiences and behaviours of international students in South Korea.

Fourth, the current study only recruited 100 participants in South Korea. A quantitative study or a large-size study can be conducted in order to collect more data from international students and professionals in South Korea. The future research studies may employ the quantitative tools in order to expand the overall performance. More importantly, both current research study and future research studies should be promoted to the governmental agencies, policymakers' offices, and NGOs in order to express the concerns in South Korea. 
Last but not least, there are additional schools and scholars that defined neo-racism or cultural-racism differently. For example, some scholars advocated that neo-racism should include skin colour as one of the key elements for investigation. However, the current definition of neo-racism tends to focus on the issues about minorities, foreigners, rural residents, gender issues, diaspora, social status, stigma, and people's nationality, birthplace, place of origin, religious practices, etc. (i.e. beyond skin colour). Therefore, the wider scope has been employed. In the future, research studies may focus on a single or multiple scope(s) in order to create a focus.

\subsection{Conclusions}

The current study investigated the challenges and difficulties of international students who are currently enrolled at one of the South Korean universities and graduate schools based on the lens of neo-racism theory [14]. The results of this study outlined that international students faced discriminations based on their nationalities, place of origin, religious practices, personal characteristics, and gender inside and outside of the university environment. Although many participants tried to seek help from the community centres and university staff, many South Korean agencies and officers refused to provide assistance and convinced the participants to accept the cultural challenges. As a result, many of the participants were not satisfied with their academic and living experiences and will leave the region after their graduation.

As an implication of this social problem, based on the results of this study, the researcher suggested that the government agencies should coordinate with the school leaders, local community offices, NGOs, and researchers to reform and polish their current policies and regulations for international students and professionals to overcome the challenges. More importantly, the Ministry of Education and school leaders should promote appropriate education schemes and programmes for intercultural understanding and education. As South Korean is seeking to become one of the growing regions in the East Asian region, it is important to update both hardware and software of the local residents. Otherwise, the social-cultural challenges and difficulties may limit the investment and development of international professionals in the region.

\section{Acknowledgments}

The research was supported by Woosong Academic Research Funding 2020.

\section{REFERENCES}

[1] M. Koh and M. Kim, "Number of international students rises to all-time high in South Korea," Maeil Business News Korea, Seoul, South Korea, Aug. 30, 2019.

[2] "Systematic support programs from the government," Education National Institute for International, 2019. https://www.studyinkorea.go.kr/en/overseas_info/allnew_g overnmentalSupport.do (accessed Oct. 03, 2020).

[3] S. W. Lee, "Circulating East to East: Understanding the Push-Pull factors of Chinese students studying in Korea," $J$. Stud. Int. Educ., vol. 21, no. 2, pp. 170-190, May 2017, doi: $10.1177 / 1028315317697540$.

[4] A. Ahern, T. O'Connor, G. McRuairc, M. McNamara, and D. O'Donnell, "Critical thinking in the university curriculum the impact on engineering education," Eur. J. Eng. Educ., vol. 37, no. 2, pp. 125-132, May 2012, doi: $10.1080 / 03043797.2012 .666516$.

[5] C. Lim, J. Ryu, T. Martindale, N. Kim, and S. Park, "Learning, design, and technology in South Korea: A report on the AECT- Korean Society for Educational Technology (KSET) panel discussion," TechTrends, vol. 63, no. 5, pp. 503-505, Sep. 2019, doi: 10.1007/s11528-019-00418-x.

[6] G.-S. Han, "K-Pop nationalism: Celebrities and acting blackface in the Korean media," Continuum (N. Y)., vol. 29, no. 1, pp. 2-16, Jan. 2015, doi: 10.1080/10304312.2014.96 8522.

[7] "Korean Government Support Program for Foreign Exchange Students," National Institute for International Education, 2019. https://www.studyinkorea.go.kr/en/sub/gk s/allnew_exchange.do (accessed Oct. 03, 2020).

[8] "Education of international students," Ministry of Education National Institute for International Education, 2020. https://www.studyinkorea.go.kr/en/sub/overseas_info/korea _edu/edu_student.do (accessed Sep. 20, 2020).

[9] H. N. Suh, L. Y. Flores, and K. T. Wang, "Perceived discrimination, ethnic identity, and mental distress among Asian international students in Korea," J. Cross. Cult. Psychol., vol. 50, no. 8, pp. 991-1007, Sep. 2019, doi: $10.1177 / 0022022119874433$.

[10] S. Noh, V. Kaspar, and K. A. S. Wickrama, "Overt and subtle racial discrimination and mental health: Preliminary findings for Korean immigrants," Am. J. Public Health, vol. 97, no. 7, pp. 1269-1274, Jul. 2007, doi: 10.2105/AJPH.2005.085316.

[11] L. M. Dos Santos, "Stress, burnout, and turnover issues of Black expatriate education professionals in South Korea: Social biases, discrimination, and workplace bullying," Int. J. Environ. Res. Public Health, vol. 17, no. 11, p. 3851, 2020, doi: 10.3390/ijerph17113851.

[12] L. M. Dos santos, "Becoming university language teachers in South Korea: The application of the interpretative phenomenological analysis and social cognitive career theory," J. Educ. e-Learning Res., vol. 7, no. 3, pp. 250-257, 2020, doi: 10.20448/journal.509.2020.73.250.257.

[13] T. Hui, M. Yuen, and G. Chen, "Career-Related Filial Piety and Career Adaptability in Hong Kong University Students," Career Dev. Q., vol. 66, no. 4, pp. 358-370, Dec. 2018, doi: 
$10.1002 / \mathrm{cdq} .12156$.

[14] M. Barker, The new racism: Conservatives and the ideology of the tribe. London, UK: Junction Books, 1981.

[15] L. M. Dos Santos, "Experiences and expectations of international students at historically black colleges and universities: An interpretative phenomenological analysis," Educ. Sci., vol. 9, no. 3, p. 189, Jul. 2019, doi: 10.3390/educsci9030189.

[16] J. Lee, J. Jon, and K. Byun, "Neo-racism and neo-nationalism within East Asia," J. Stud. Int. Educ., vol. 21, no. 2, pp. 136-155, May 2017, doi: $10.1177 / 1028315316669903$.

[17] K. H. Tang and L. M. Dos Santos, "A brief discussion and application of interpretative phenomenological analysis in the field of health science and public health," Int. J. Learn. Dev., vol. 7, no. 3, pp. 123-132, Aug. 2017, doi: 10.5296/ijld.v7i3.11494.

[18] C. Moustakas, Phenomenological research methods. Thousand Oaks, CA: Sage, 1994.

[19] D. R. Thomas, "A general inductive approach for analysing qualitative evaluation data," Am. J. Eval., vol. 27, no. 2, pp. 237-246, Jun. 2006, doi: 10.1177/1098214005283748.

[20] A. Pilkington, "The interacting dynamics of institutional racism in higher education," Race Ethn. Educ., vol. 16, no. 2, pp. 225-245, Mar. 2013, doi: 10.1080/13613324.2011.6462 55.

[21] H. Tajfel and J. C. Turner, "The social identity theory of intergroup behaviours," in Psychology of intergroup relations, Chicago, IL: Nelson-Hall Publishers, 1986, pp. 724.

[22] H. Tajfel, Social identity and intergroup relations. Cambridge, UK: Cambridge University Press, 2010.

[23] H. Tajfel, "Cognitive aspects of prejudice," J. Biosoc. Sci., vol. 1, no. S1, pp. 173-191, Sep. 1969, doi:

\section{$10.1017 / \mathrm{S} 0021932000023336$.}

[24] H. Tajfel, "Quantitative Judgement in Social percetion," $B r$. J. Psychol., vol. 50, no. 1, pp. 16-29, Feb. 1959, doi: 10.1111/j.2044-8295.1959.tb00677.x.

[25] E. Goffman, Stigma: Notes on the management of spoiled identity. Englewood Cliffs, N.J.: Prentice-Hall, 1963.

[26] J. Power, "Professor calls foreign student a 'low animal,"” Korea Herald, 2013. www.koreaherald.com/view.php?ud= \%0A20130429000738 (accessed Sep. 20, 2020).

[27] N. Heo, "“We are not simply "multicultural"': intersecting ethnic and religious identities of Japanese-Korean young adults in South Korea," Ethn. Racial Stud., vol. 41, no. 15, pp. 2750-2769, Dec. 2018, doi: 10.1080/01419870.2017.14 01731 .

[28] J. Yi and G. Jung, "Debating multicultural Korea: Media discourse on migrants and minorities in South Korea," $J$. Ethn. Migr. Stud., vol. 41, no. 6, pp. 985-1013, May 2015, doi: 10.1080/1369183X.2014.1002202.

[29] J. Kim and H. Jeon, "Anti-multiculturalism and the future direction of multicultural education in South Korea," Curric. Perspect., vol. 37, no. 2, pp. 181-189, Oct. 2017, doi: $10.1007 / \mathrm{s} 41297-017-0025-7$.

[30] J. Kim, "Racism, equity, and quality of education for international students in South Korean higher education institutes," Front. Educ. China, vol. 11, no. 3, pp. 338-355, 2016, doi: 10.3868/s110-005-016-0027-3.

[31] J. Kim, "Iamafeminist as the 'mother tag': Feminist identification and activism against misogyny on Twitter in South Korea," Fem. Media Stud., vol. 17, no. 5, pp. 804-820, Sep. 2017, doi: 10.1080/14680777.2017.1283343.

[32] L. M. Dos Santos, "The relationship between teachers and school professional staff's retention and managerial styles," J. Educ. e-Learning Res., vol. 7, no. 1, pp. 42-48, 2020, doi: 10.20448/journal.509.2020.71.42.48. 